\title{
Roles of activin and its signal transduction mechanisms in reproductive tissues
}

\author{
Jean-François Ethier and Jock K. Findlay \\ Prince Henry's Institute of Medical Research, PO Box 5152, Clayton, Victoria 3168, Australia
}

\begin{abstract}
Activins were identified initially as gonadal proteins having a stimulating effect on FSH production by the pituitary gland. Strong evidence has accumulated that activins are important regulating factors for many reproductive processes. Activin may have paracrine or autocrine roles rather than solely an endocrine action on FSH secretion. Activins together with their signalling molecules must be shown to be produced locally in a particular tissue to provide support for their paracrine or autocrine action in that tissue. The discovery of the activin receptors, the intracellular signalling mediators (Smads) and some transcription co-factors involved in activin responses has helped to unravel the activin-transforming growth factor $\beta$ signalling mechanism. However, few reports have clearly demonstrated the presence of all of the activin signalling molecules in reproductive tissues, despite the important roles of activin in these tissues. Several activin receptor types and Smad molecules have been identified, indicating either a redundancy in signalling molecules or different signalling pathways. At present, it is not clear which particular subset of these signalling molecules is important in reproductive processes. The aim of this review is to collate the information available on activin actions, as well as on the signalling molecules, to understand how activins may transduce their paracrine or autocrine signals in reproductive tissues.
\end{abstract}

The discovery of many cytokines and differentiation factors in recent years has stressed the importance of paracrine and autocrine activities in reproduction. Among these molecules, activins are of prime importance. Discovered in 1986 (Mathews, 1994), many studies have since demonstrated that activins are involved in the regulation of several reproductive processes in higher vertebrates. The biologically active form of activin is composed of two $\beta$ subunits covalently attached by a single disulphide link. So far, five $\beta$-subunits have been identified $\left(\beta_{\mathrm{A}}\right.$ to $\beta_{\mathrm{E}}$ ) (Woodruff, 1998), but only the $\beta_{\mathrm{A}^{-}}$and $\beta_{\mathrm{B}}$-subunits have been shown to dimerize, giving three possible types of activin species (Fig. 1), which are named according to the subunit species of which they are composed (activin A, B and $A B$ ). The $\beta_{A^{-}}$and $\beta_{B}$-subunits can also heterodimerize with the related $\alpha$-subunit to form the activin antagonist inhibin. The activin-inhibin subunits are structurally related to the transforming growth factor $\beta$ (TGF- $\beta$ ) family of peptides, which also includes bone morphogenetic proteins (BMP), Müllerian inhibiting substance (MIS) and growth and differentiation factors (GDF) (Kingsley, 1994). This review concerns the information available on how activins may transduce their signals in reproductive tissues. Owing to an

Email: j.f.ethier@med.monash.edu.au abundance of reports, it is not possible to provide an exhaustive list of activin actions. Nevertheless, the actions most relevant to this review are first discussed, and then the distribution of activin and its signalling components in these tissues are described to demonstrate the presence of a functional activin signalling pathway.

\section{Roles of activins in reproductive processes}

\section{Roles of activins in the female}

Originally, activins were regarded as acting mainly in the gonadal-pituitary axis since they were identified as gonadal proteins capable of positive regulation of pituitary FSH secretion. Several studies have since confirmed this activity on FSH production as well as on other pituitary produced proteins, such as follistatin (Phillips and de Kretser, 1998; Woodruff, 1998).

Subsequently, the quest for factors regulating folliculogenesis has led to the observation that activins may be important intraovarian regulators (Findlay, 1993). It is now accepted that activin can modulate many ovarian cell functions, at least in vitro. One of the critical steps during folliculogenesis is the acquisition of FSH responsiveness by the follicles. It has been demonstrated, using diethylstilboestrol-treated immature rat granulosa cells, that activin A potentiates $\mathrm{FSH}$-stimulated aromatase activity, as 


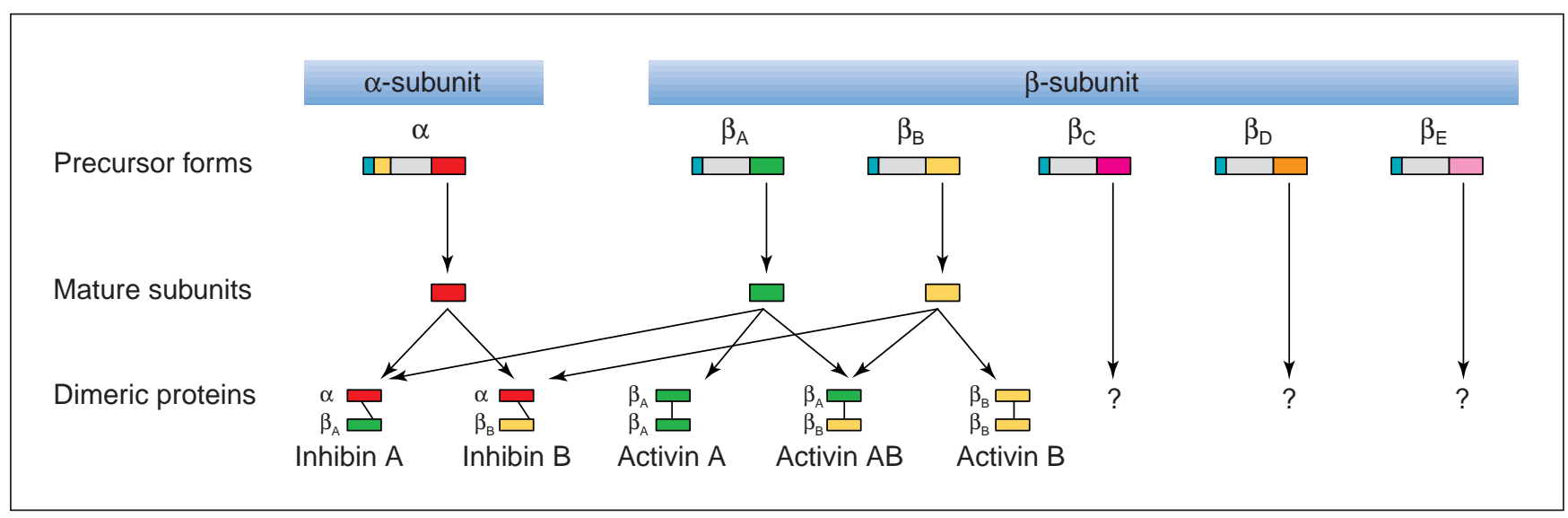

Fig. 1. Schematic representation of inhibins and activins. The subunit peptides are synthesized initially as precursors, which are then processed to release the mature C-terminal portions. An $\alpha$-subunit can associate with either $\beta$-subunits to form inhibin A or inhibin B. The $\beta$-subunits can also dimerize to form the activins. The dimerization of the $\beta C, \beta D$ and $\beta E$-subunits have not yet been demonstrated.

well as progesterone and inhibin production (Findlay, 1993). The increase in FSH sensitivity is not due to a change in $\mathrm{FSH}$ receptor affinity but rather to an increase in FSH receptor mRNA (Nakamura et al., 1993) as well as in the number of FSH receptors at the cell surface (Findlay, 1993). When administered alone, the effect of activin on gonadotrophin receptors is selective to the $\mathrm{FSH}$ receptor but, in the presence of $\mathrm{FSH}$, activin $\mathrm{A}$ increases the $\mathrm{FSH}$ driven expression of the LH-hCG receptor mRNA (Kishi et al., 1998). Activin A can also have a mitogenic effect on these immature granulosa cells as demonstrated by an increase in $\left[{ }^{3} \mathrm{H}\right]$ thymidine uptake. $\mathrm{FSH}$ administered alone had no effect on DNA replication, but it becomes mitogenic when administered with activin A (Miro and Hillier, 1996). These data indicate that activin A may have a role in controlling the proliferation and maturation of granulosa cells.

Many studies have further demonstrated that activin A has a direct effect on the synthesis of various ovarian hormones. For example, cultured granulosa cells from immature rats increase their inhibin $\alpha$-subunit mRNA and protein biosynthesis in the presence of activin (LaPolt et al., 1989). In contrast, in human granulosa-luteal cells, activin A does not affect the $\alpha$-subunit mRNA or the $\beta_{\mathrm{A}}$-subunit steady state concentrations, but it can increase the amount of $\beta_{\mathrm{B}}$-subunit mRNA (Eramaa et al., 1995). Activin A can also modulate steroidogenesis, as demonstrated by the decrease of progesterone secretion by bovine preovulatory granulosa cells (Shukovski and Findlay, 1990) and by the decrease in hCG-stimulated progesterone secretion in human granulosa cells (Woodruff, 1998). Activin also acts on theca cells to inhibit $\mathrm{LH}$-induced androgen production (Findlay, 1993) and on oocytes to enhance their maturation (Alak et al., 1998).

The effect of activin A on cultured follicles has been studied and it has been found that, in addition to a growthstimulating effect on follicles from immature animals (Liu et al., 1998), activin A promotes the reorganization of follicular structures in the presence of FSH in vitro (Li et al., 1995). However, this growth-promoting action seems to be age-specific since it has been shown that activin A cannot increase the size of follicles from adult animals (Liu et al., 1999). In fact, activin A blocks the FSH-induced growth of preantral follicles from adult mice (Liu et al., 1999; Mizunuma et al., 1999). It has been further demonstrated that follistatin can block the dominance of secondary follicles on small preantral follicles, indicating that activin from secondary follicles causes small preantral follicles to become dormant (Mizunuma et al., 1999).

\section{Roles of activins in the male}

Activins appear to be as important for male as they are for female reproductive processes (Risbridger and Cancilla, 2000). For example, activin A stimulates proliferation of testicular cells from immature rats (Boitani et al., 1995). However, as they appear to be in female gonads, activin actions on testicular cells are age-specific. In the presence of FSH, activin A stimulates the proliferation of Sertoli cells from 9-day-old rats but not from 18-day-old rats (Boitani et al., 1995). Another study that used transgenic mice overexpressing the $\beta_{A}$-subunit mainly in the testis indicated that the control of the expression of the $\beta_{\mathrm{A}}$-subunit is critical for male gonadal functions (Tanimoto et al., 1999). In this study, the transgenic mice became infertile, probably as a result of a deficiency in spermatogenesis. However, since the testes produce the $\alpha$-subunit together with the $\beta_{\mathrm{A}^{-}}$ subunit, it is not clear whether this sterility was due to an excessive amount of inhibin or activin.

Most of the data on activin actions described above have been collected using activin A. It remains unknown whether activin $B$ and $A B$ possess the same activity for the biological effects described in this review. Nevertheless, the few existing data on the activity of activin $\mathrm{B}$ indicate that it is 
similar to that of activin A (Corrigan et al., 1991), although this remains to be confirmed.

\section{Expression of activins in reproductive tissues}

Sites of activin production are widespread and often overlap with their sites of action, leading to the hypothesis that activins have paracrine or autocrine actions in reproduction. Consistent with this hypothesis, circulating amounts of activin A vary only slightly during the menstrual cycle (Muttukrishna et al., 1996), in contrast to inhibin concentrations, which fluctuate over the cycle (Woodruff, 1998). In addition, the changes in serum activin concentrations with age do not correlate with changes in $\mathrm{FSH}$ concentrations, and the circulating activin A is sequestered by binding proteins such as follistatin, which may decrease its bioavailability (Loria et al., 1998).

\section{Pituitary gland}

Early studies have localized the inhibin and activin subunits in the pituitary. One of these studies has shown that the $\beta_{B}$-subunit is detected in gonadotropes while the $\beta_{\mathrm{A}}$-subunit was not immunodetected, suggesting that the pituitary produces mainly activin B or inhibin B (Roberts et al., 1989). However, a study on human pituitaries showed that the activin A dimer was present, but mainly in somatotrophs (Wada et al., 1996).

\section{Ovary}

In the human ovary, the $\beta_{\mathrm{A}}$-subunit mRNA is found in the granulosa and theca cells of dominant follicles and in the corpus luteum. In the small antral follicles, a weak expression was also observed in granulosa cells, but not in

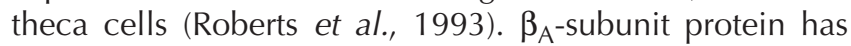
been mainly detected in granulosa cells (Yamoto et al., 1992) and occasionally in theca cells of small antral follicles, despite the absence of its mRNA (Roberts et al., 1993). Roberts et al. (1993) also reported the detection of $\beta_{A}$-subunit in luteal cells. The production of the $\beta_{A}$-subunit in primordial and preantral follicles does not appear to be modulated during the menstrual cycle. However, in medium antral follicles and preovulatory follicles, the production of the $\beta_{\mathrm{A}}$-subunit appears to be cycledependent, since it was mainly immunodetected during the midfollicular and late follicular phases, respectively (Yamoto et al., 1992). Unfortunately, Yamoto et al. (1992) did not give any information on whether the granulosa cells use the $\beta_{\mathrm{A}}$-subunit to produce inhibin $\mathrm{A}$ or activins. A study designed to clarify this issue used an anti-activin A antibody with relatively low crossreactivity for inhibin and demonstrated that activin A is present exclusively in the granulosa cells of mature follicles and in the corpus luteum (Wada et al., 1996).

The distribution of expression of the $\beta_{B}$-subunit gene in the ovary is significantly different from that of the $\beta_{A}$-subunit gene. In contrast to the $\beta_{A}$-subunit mRNA, the $\beta_{B}$-subunit messenger is present in high abundance in the granulosa cells of small antral follicles, but was below detection in dominant follicles (Roberts et al., 1993). This switch of $\beta_{B^{-}}$ subunit expression may indicate that the $\beta$-subunits have different roles to play during the maturation of the follicle. However, a switch in $\beta$-subunit expression does not necessarily indicate a change in the type of activin formed. The ovary is a major source of inhibin $A$ and $B$, the serum concentrations of which change during the menstrual cycle, indicating that the change of subunit expression may reflect a switch in inhibin rather than activin species production. However, Yamoto et al. (1992) could not detect any major difference in the distribution of the $\beta_{\mathrm{A}}$ and $\beta_{\mathrm{B}}$-subunit proteins. Both peptides had the same cycle-independent distribution in primordial or preantral follicles and showed a similar cycle-dependent distribution in small antral and dominant follicles. Thus, it remains unclear whether activin $A$ and $B$ have different roles during folliculogenesis.

\section{Testis}

In adult rat testes, the mRNAs encoding the $\beta$-subunits were localized in the Sertoli cells and their expression was dependent on the seminiferous epithelial cycle. The $\beta A$ subunit mRNA starts to appear at stage VIII, reaching a maximum at stages IX-XI, whereas maximum $\beta_{\mathrm{B}}$-subunit mRNA concentrations are observed at stage XIII (Kaipia et al., 1992). However, despite the presence of its mRNA, the $\beta_{\mathrm{A}}$-subunit protein was not detected in the rat testes, although, in men, the activin A dimer was detected in Leydig and Sertoli cells (Wada et al., 1996).

The protein distribution and the developmental expression of $\beta_{\mathrm{B}}$-subunits in the testes appear to be different from those of the $\beta_{A}$-subunit, at least in rats. During development, $\beta_{A}$-subunit synthesis was immunodetected in fetal Leydig cells but the signal decreased markedly after birth, whereas the $\beta_{\mathrm{B}}$-subunit was detected in the Sertoli cells and its abundance increased after birth (Majdic et al., 1997), indicating different roles for the $\beta$-subunits during the testicular maturation.

\section{Endometrium}

In the early stages of the menstrual cycle, the $\alpha$ and $\beta$ subunits were detected in the human endometrium, primarily in glandular epithelium (Leung et al., 1998; Otani et al., 1998; Jones et al., 2000). During early pregnancy, the endometrium also produces all three inhibin-activin subunits (Otani et al., 1998; Jones et al., 2000). The $\beta_{A}$ and $\beta_{B}$ subunits were also detected in a subset of uterine leukocytes and expression of $\alpha$ - and $\beta$-subunits in decidualized stromal cells was upregulated after the onset of decidualization (Jones et al., 2000). These data imply a role for inhibin or activin in decidualization but the exact physiological roles of activin $A$ in the uterus and in pregnancy remain obscure. However, there is an interesting correlation between circulatory concentrations of activin A and pregnancy. During pregnancy, activin B is generally 
absent from the maternal circulation, but circulatory concentrations of activin A increase to tenfold higher than the menstrual cycle concentrations (Petraglia et al., 1994; Muttukrishna et al., 1996). Furthermore, serum activin A concentrations are significantly higher in women undergoing spontaneous labour compared with women undergoing elective caesarean section, indicating a role in human parturition (Petraglia et al., 1994). This increase in activin A is probably due to its synthesis by decidual and placental tissues rather than by corpora lutea (Otani et al., 1998).

\section{Signalling mechanisms}

Activins are secreted proteins and, as for any external stimulus, responsive cells must bear the proper mechanism to transduce the activin signal intracellularly. Since the cloning of the first cDNA encoding the activin type II receptor a decade ago, a tremendous amount of knowledge has been acquired about the signalling mechanisms of many members of the TGF- $\beta$ family.

Like most members of the TGF- $\beta$ family, activins mediate their actions by binding to a complex of transmembrane serine and threonine kinase receptors. So far, four activin receptors have been identified by their ability to bind activin. These proteins can be classified into two main categories, namely the type I receptor group, comprising the activin receptor-like kinase ALK2 and ALK4, and the type II receptor group, comprising the activin type II and type IIB receptors (ActRII and ActRIIB) (Mathews, 1994; Hoodless and Wrana, 1998). In addition, five isoforms of ActRIIB, generated by alternative splicing of its mRNA, have been identified in mice and bovine species (Attisano et al., 1992; Ethier et al., 1997). Thus, activins have the potential to act through several forms of receptors. In fact, to transmit its signal into the targeted cells, several studies indicate that activin must act through a receptor complex made of type I and type II receptors. It is thought that activin binds first to an activin type II receptor, and then an activin type I receptor is recruited into the complex (Fig. 2a). The formation of this ligand-receptor complex induces the activation of the type I receptor by the kinase activity of the nearby type II receptor (Mathews, 1994).

Once activated, the kinase of the activin type I receptor stimulates the downstream pathways. The only direct substrates identified to date form a novel family of proteins called Smads. These proteins can be grouped in three subclasses: the receptor-activated Smads, the common Smads and the inhibitory Smads (Table 1) (Attisano and Wrana, 1998). Activin can signal specifically through Smad2 and Smad3. Once Smad2 or Smad3 are activated by phosphorylation, they associate with Smad4 and the dimer migrates to the nucleus. The Smad complex can then bind to specific promoters and associate with transcriptional cofactors and co-activators to induce a transcriptional response (Massague and Chen, 2000).

Specific roles, in terms of activin actions, for the different activin receptors are not clear at present. Nevertheless, the
Table 1. Subclasses in the intracellular signalling mediator (Smad) family

\begin{tabular}{ll}
\hline Subclass & Signalling specificity \\
\hline Receptor-activated & \\
Smad1 & BMP \\
Smad2 & Activin and TGF- $\beta$ \\
Smad3 & Activin and TGF- $\beta$ \\
Smad5 & BMP \\
Smad8 & BMP \\
Common & \\
Smad4 & Necessary for activin, TGF- $\beta$ and BMP \\
& signalling \\
Inhibitory & \\
Smad6 & Preferentially BMP \\
Smad7 & Preferentially activin and TGF- $\beta$ \\
\hline
\end{tabular}

Mammalian Smads are clustered in three groups according to their functional characteristics. The receptor-regulated Smads respond to a specific external signal.

BMP: bone morphogenetic protein; TGF- $\beta$ : transforming growth factor- $\beta$.

creation of activin receptor-deficient mice showed that the type II and type IIB receptors may be functionally different, not only during embryogenesis but also for the maintenance of fertility. The majority of the ActRIIB-deficient mice died soon after birth, but some survived and both males and females were shown to be fertile (Oh and $\mathrm{Li}, 1997$ ), indicating that an ActRIIB-derived signal is not essential for reproductive processes. In contrast, most of the ActRIIdeficient mice were viable but their reproductive ability was impaired. For example, the males had reduced testicular size and their attainment of reproductive maturity was delayed, while the females were infertile, probably owing to a block in folliculogenesis (Matzuk et al., 1995). Nevertheless, the finding that the ActRII-deficient males were fertile indicates that the ActRII-mediated signal is not critical for spermatogenesis. In both male and female ActRII knock-out mice, the FSH concentrations were decreased compared with control mice, indicating that the impairment in fertility may be the result of low concentrations of FSH. This finding also indicates that the signal transduced through ActRII in the gonadotropes is essential to maintain the $\mathrm{FSH}$ concentrations and cannot be replaced by an ActRIIB-mediated signal. This functional divergence between ActRII and ActRIIB may be explained by the activation of separate pathways leading to different transcriptional outcomes. However, it is also possible that ActRII and ActRIIB transduce a similar signal but that their distribution may not overlap in regions important for $\mathrm{FSH}$ regulation, explaining why ActRIIB cannot rescue an ActRII deficiency. The targeted disruption of the genes encoding the activin type I receptors ALK2 (Gu et al., 1999) and ALK4 (Gu et al., 1998) and the various Smads (Nomura and Li, 1998) clearly indicates that they are important embryogenic 
factors but, since a systemic deficiency in these proteins leads to embryonic lethality, it is impossible to evaluate their roles in reproductive physiology. Studies using tissuespecific and temporal disruption of these genes are necessary to obtain further details on their physiological relevance in reproductive tissues.

Obviously, the regulation of activin signalling is very important. A complete examination of the mechanisms involved in the control of activin activity is beyond the scope of this review. Nevertheless, it is worth mentioning that at least two secreted proteins are involved in the extracellular control of activin bioactivity. Follistatin is a high-affinity activin-binding protein that prevents the access of activin to its receptors (Phillips and de Kretser, 1998) (Fig. 2b). The second extracellular antagonist is inhibin, the molecular mechanism of action of which remains poorly understood. However, inhibin is thought to exert its antagonistic effects by competing with activin for the binding of the activin receptor complex, although there is evidence that inhibin may interact with its own specific membrane proteins (Robertson et al., 2000). The identification of Betaglycan (Lewis et al., 2000) and p120 (Chong et al., 2000) as inhibin-binding proteins that may act as accessory proteins in this process should help in the elucidation of its antagonistic mechanism (Fig. 2b). The activin signal can also be regulated intracellularly. Among the inhibitory Smads, Smad7 can specifically downregulate the activin signal by preventing the activation of the activinstimulated Smads (Fig. 2c). In addition, a growing list of intracellular proteins that have a negative effect on the activin-TGF- $\beta$ signal is being identified. None of these proteins have been directly implicated in reproductive processes to date and, therefore, they will not be discussed in this review (for an excellent review, see Massague and Chen, 2000).

\section{Expression of activin receptors in reproductive tissues}

\section{Activin receptors in the ovary}

Distribution analysis using ${ }^{125}$-labelled activin A showed that activin A accumulates mainly in the ovary, the pituitary, the testis and the bone marrow in immature and adult rats, indicating the presence of activin receptors in these tissues (Mathews, 1994). Further ligand binding studies in situ in the ovary showed that activin binds to the granulosa cells during all phases of the rat ovarian cycle, as well as to the theca cells of developing follicles, while the corpus luteum showed ${ }^{125}$-labelled activin binding during metoestrus and dioestrus (Woodruff et al., 1993). Consistent with these activin-binding studies, expression of the activin receptors genes has been detected in the ovary. Northern blotting and RT-PCR detected ALK2 and ALK4 mRNAs in granulosa-luteal cells of human ovaries (Eramaa et al., 1995; Peng et al., 1999). In the rat ovary, in situ hybridization studies showed that ALK2 mRNA was localized mainly in the oocytes of preantral and antral follicles but, in contrast to the situation in the human ovary, the ALK4 mRNA was not detectable (He et al., 1993), indicating a species difference or a lack of sensitivity with the in situ hybridization technique used in the rat study. Much more information is available on the gene expression of both activin type II receptors. Northern blotting showed that the mRNAs encoding ActRII and ActRIIB were seen in the bovine and rat corpus luteum (Cameron et al., 1994; Ethier et al., 1994, 1997). Another study showed the presence of ActRII mRNA in ovaries of immature, cyclic and pregnant rats (Feng et al., 1993). In situ hybridization studies have localized a strong signal for the ActRII mRNA over the oocytes as well as a moderate signal in granulosa cells (Cameron et al., 1994). In the human ovary, the available data are inconsistent since ActRII mRNA was detected in the granulosa-luteal cells in an RT-PCR study (Peng et al., 1999) but not in a study using the in situ hybridization technique (Roberts et al., 1994). The localization of expression of the ActRIIB gene is also unclear. Some studies have detected the messenger in the oocytes and in the granulosa cells (Cameron et al., 1994; Eramaa et al., 1995; Peng et al., 1999) whereas other studies failed to detect it (Aloi et al., 1997; Roberts et al., 1994).

Since the activin subunits have a cycle-dependent distribution in antral follicles and since activin has been demonstrated to affect follicular growth and FSH sensitivity, a modulation in the expression of the activin receptors might be expected to occur during the ovarian cycle. Unfortunately, at present, no reports are available on the modulation of the activin receptor gene expression during the ovarian cycle. Nevertheless, most of the data collected to date tend to indicate that the amounts of activin receptor mRNA can vary during the oestrous cycle in rats, especially in granulosa and luteal cells. For example, amounts of ALK2 and ActRII mRNA have been shown to be modulated during the rat oestrous cycle, increasing during the dioestrous phase (Cameron et al., 1994) and decreasing after the pro-oestrous gonadotrophin surge (Aloi et al., 1997). In contrast, in the oocytes, the amount of ActRII mRNA remained very high regardless of the stage of folliculogenesis or oestrous cycle.

\section{Activin receptors in the testis}

Much less is known about the expression of the activin receptors in the testes. The ALK2 gene is expressed in bovine testes, and there is a change in messenger species profile during testicular maturation (J-F. Ethier, unpublished). The ActRII mRNA has been detected in whole bovine and mouse testes by Northern blot analysis (Ethier et al., 1994; Wu et al., 1994). In rats, at the cellular level, ActRII appears to be expressed mainly in spermatogenic cells and, depending on the study, the ActRII mRNA is present at a very low level or absent in Sertoli cells (Kaipia et al., 1992; Cameron et al., 1994). The ActRIIB mRNA was also detected in bovine and mouse testes (Wu et al., 1994; Ethier et al., 1997) but its cellular localization is unclear, 


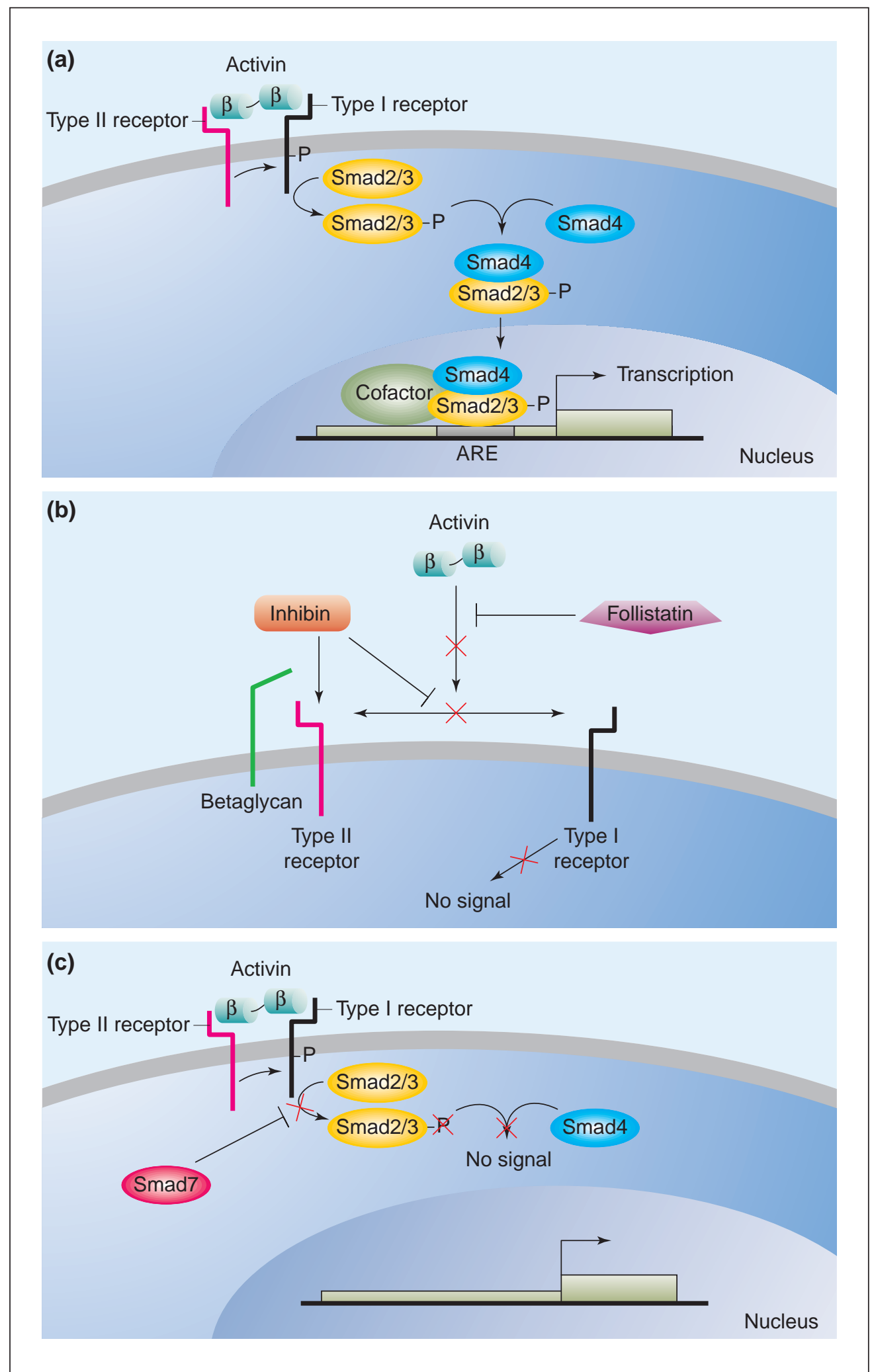

Fig. 2. Model of the signalling mechanism of activin and of its regulation. (a) Signalling mechanism: activin binds to the activin type II receptors, which in turn recruit and phosphorylate the type I receptors. The activin type I receptors transduce the activin signal by phosphorylating the activin-TGF- $\beta$-specific Smad2 or Smad3. Once phosphorylated, Smad2 or Smad3 dimerizes with the common Smad, Smad4. The dimer is then translocated into the nucleus, where it associates with cell-specific transcriptional co-factors. The Smad complex can bind directly to the activin response elements (ARE) of activin responsive promoters. It has been suggested that the Smad complex can 
since one study detected the ActRIIB mRNA mainly in Leydig and interstitial cells (Cameron et al., 1994) while another localized it in type A1 and A2 spermatogonia and in Sertoli cells (Kaipia et al., 1993).

\section{Activin receptors in the pituitary}

In correlation with the action of activin on FSH secretion, the mRNAs for ActRII and ActRIIB have been detected in bovine and rat pituitary (Cameron et al., 1994; Ethier et al., 1994, 1997). The ActRIIB mRNA appears to be associated with gonadotropes in prepubertal rats (Wilson and Handa, 1998).

\section{Expression of intracellular mediators of the activin signal}

A cell needs to be equipped with the complete intracellular machinery involved in activin signalling to be responsive to activins. The information available on the distribution of the Smad proteins in reproductive tissues is extremely limited. The Smad2 protein has been reported to be present in hen granulosa cells at different stages of follicular development, with maximum concentrations occurring during the early stages of folliculogenesis (Li et al., 1997). The Smad2 mRNA has also been detected in human oocytes by RT-PCR. An immunoreactive signal was observed over oocytes using an antibody crossreacting with Smad2 and Smad3, indicating the production of Smad2 protein by the oocytes (Osterlund and Fried, 2000). Smad3 mRNA was detected in mouse granulosa cells (Kano et al., 1999). The mRNAs for Smad2, Smad3 and Smad4 have been detected in the ovaries of postnatal rats and the Smad 2 and Smad 4 proteins have been immunodetected within the oocytes, the theca and granulosa cells (A. E. Drummond, unpublished). The colocalization of activin-regulated Smads with the activin receptors in oocytes and granulosa cells indicates the presence of a functional activin signalling pathway and supports the hypothesis that activin has paracrine-autocrine roles in the ovary. Finally, mRNAs for Smad 1-7 have been identified in cultured Leydig cells, indicating the presence of a functional pathway in these cells (Goddard et al., 2000).

\section{Conclusion}

Consistent with the actions of activin, activin signalling components appear to be present in most reproductive tissues. For some tissues, the question of cell-specificity of response to activin can be addressed by examining the sites of receptor and Smad expression. For instance, it is clear that the oocytes and the granulosa cells may be under activin regulation. However, many questions remain unanswered. How can activin have age- and stage-specific effects during folliculogenesis? Which subset of receptors and Smads are involved? Does a switch in the expression of the signalling components explain the various effects of activin? The next challenge will be to obtain a better understanding of the distribution and temporal expression of these activin signalling components and to determine which components are responsible for the specificity of the activin effect. Some studies are now indicating that, under some circumstances, Smad2 and Smad3 are functionally different. Moreover, ALK2 and ALK4 appear to stimulate different pathways (J-F. Ethier, unpublished) and it has been suggested that ALK2 transduces a BMP-like signal. The activation of a particular pathway in preference to any other may explain the differential responsiveness to activin.

The model of activin signalling implies several levels of complexity to permit the differential responses. It is conceivable that the Smad pathway is the core of the activin signalling mechanism but, depending on the cell context, it would have to be modulated by cell-specific intracellular factors. These differentially expressed factors would associate with the activated Smads to induce specific promoters. Unfortunately, as yet, no such intracellular modulators have been associated with any specific action of activin in reproductive tissues. The search for such putative modulators is of great importance to the understanding of how activin modulates the different reproductive processes discussed in this review.

Further studies are needed to determine whether activin $A, B$ and $A B$ (and likewise, inhibin $A$ and $B$ ) are functionally similar. The results of such studies will help in the understanding of the significance of the observation that most reproductive tissues exhibit a differential expression of $\beta$-subunits at some stage. In addition, it is important that the cellular mechanisms responsible for the specific production of activin and inhibin species are identified.

The authors would like to thank Dr Rebecca Jones and Dr Ann Drummond for stimulating discussions. They are also grateful to S. Panckridge for her professional help with the figures. The authors are supported financially by a Program grant from the National Health and Medical Research Council of Australia (Regkey 983212) and a fellowship from FCAR funds, Canada.

recruit coactivators as well as corepressors, the association of which determines the induction or the suppression of a transcriptional response. (b) Extracellular antagonism of activin signalling: follistatin binds activin with high affinity and prevents binding of activin to its receptors. Inhibin also modulates activin signalling. It has been suggested that betaglycan increases inhibin affinity to the activin type II receptor, which in turn prevents access of activin to the type II receptor and recruitment of the type I receptor. (c) Intracellular antagonism of activin signalling: the inhibitory Smad7 prevents Smad2 and Smad3 interactions with the receptor complex, thereby preventing the phosphorylation of Smad2/3. The formation of a complex with Smad4 is also prevented, thereby stopping the signalling cascade. 


\section{References}

Key references are identified by asterisks.

Alak BM, Coskun S, Friedman $\mathrm{Cl}$, Kennard EA, Kim MH and Seifer DB (1998) Activin A stimulates meiotic maturation of human oocytes and modulates granulosa cell steroidogenesis in vitro. Fertility and Sterility $701126-1130$

Aloi JA, Marshall JC, Yasin M, Gilrain JT, Haisenleder DJ and Dalkin AC (1997) Ovarian activin receptor subtype and follistatin gene expression in rats: reciprocal regulation by gonadotropins Biology of Reproduction 56 1565-1569

Attisano L and Wrana JL (1998) Mads and Smads in TGF beta signalling Current Opinion in Cell Biology 10 188-194

Attisano L, Wrana JL, Cheifetz S and Massague J (1992) Novel activin receptors: distinct genes and alternative mRNA splicing generate a repertoire of serine/threonine kinase receptors Cell 68 97-108

Boitani C, Stefanini M, Fragale A and Morena AR (1995) Activin stimulates Sertoli cell proliferation in a defined period of rat testis development Endocrinology 136 5438-5444

Cameron VA, Nishimura E, Mathews LS, Lewis KA, Sawchenko PE and Vale WW (1994) Hybridization histochemical localization of activin receptor subtypes in rat brain, pituitary, ovary, and testis Endocrinology 134 799-808

Chong H, Pangas SA, Bernard DJ, Wang E, Gitch J, Chen W, Draper LB, Cox ET and Woodruff TK (2000) Structure and expression of a membrane component of the inhibin receptor system Endocrinology $1412600-2607$

Corrigan AZ, Bilezikjian LM, Carroll RS, Bald LN, Schmelzer CH, Fendly BM, Mason AJ, Chin WW, Schwall RH and Vale W (1991) Evidence for an autocrine role of activin B within rat anterior pituitary cultures Endocrinology 128 1682-1684

Eramaa M, Hilden K, Tuuri T and Ritvos O (1995) Regulation of inhibin/activin subunit messenger ribonucleic acids (mRNAs) by activin $A$ and expression of activin receptor mRNAs in cultured human granulosa-luteal cells Endocrinology 136 4382-4389

Ethier JF, Houde A, Lussier JG and Silversides DW (1994) Bovine activin receptor type II cDNA: cloning and tissue expression Molecular and Cellular Endocrinology 106 1-8

Ethier JF, Lussier JG and Silversides DW (1997) Bovine activin receptor type IIB messenger ribonucleic acid displays alternative splicing involving a sequence homologous to Src-homology 3 domain binding sites Endocrinology 138 2425-2434

Feng ZM, Madigan MB and Chen CL (1993) Expression of type II activin receptor genes in the male and female reproductive tissues of the rat Endocrinology 132 2593-2600

Findlay JK (1993) An update on the roles of inhibin, activin, and follistatin as local regulators of folliculogenesis Biology of Reproduction 48 15-23

Goddard I, Bouras M, Keramidas M, Hendrick JC, Feige JJ and Benahmed M (2000) Transforming growth factor-beta receptor types I and II in cultured porcine leydig cells: expression and hormonal regulation Endocrinology 141 2068-2074

Gu Z, Nomura M, Simpson BB, Lei H, Feijen A, van den Eijnden-van Raaij J, Donahoe PK and Li E (1998) The type I activin receptor ActRIB is required for egg cylinder organization and gastrulation in the mouse Genes and Development 12 844-857

Gu Z, Reynolds EM, Song J, Lei H, Feijen A, Yu L, He W, MacLaughlin DT van den Eijnden-van Raaij J, Donahoe PK and Li E (1999) The type I serine/threonine kinase receptor ActRIA (ALK2) is required for gastrulation of the mouse embryo Development 126 2551-2561

He WW, Gustafson ML, Hirobe S and Donahoe PK (1993) Developmental expression of four novel serine/threonine kinase receptors homologous to the activin/transforming growth factor-beta type II receptor family Developmental Dynamics 196 133-142

*Hoodless PA and Wrana JL (1998) Mechanism and function of signaling by the TGF beta superfamily Current Topics in Microbiology and Immunology 228 235-272

Jones RL, Salamonsen LA, Critchley HOD, Rogers PAW, Affandi B and Findlay JK (2000) Inhibin and activin subunits are differentially expressed in endometrial cells and leukocytes during the menstrual cycle, in early pregnancy and in women using progestin-only contraception Molecular Human Reproduction 6 1107-1117

Kaipia A, Penttila TL, Shimasaki S, Ling N, Parvinen M and Toppari J (1992) Expression of inhibin beta $A$ and beta $B$, follistatin and activin $A$ receptor messenger ribonucleic acids in the rat seminiferous epithelium Endocrinology 131 2703-2710

Kaipia A, Parvinen M and Toppari J (1993) Localization of activin receptor (ActR-IIB2) mRNA in the rat seminiferous epithelium Endocrinology 132 $477-479$

Kano K, Notani A, Nam SY, Fujisawa M, Kurohmaru M and Hayashi Y (1999) Cloning and studies of the mouse cDNA encoding Smad3 Journal of Veterinary Medical Science 61 213-219

Kingsley DM (1994) The TGF-beta superfamily: new members, new receptors, and new genetic tests of function in different organisms Genes and Development 8 133-146

Kishi H, Minegishi T, Tano M, Kameda T, Ibuki Y and Miyamoto K (1998) The effect of activin and FSH on the differentiation of rat granulosa cells FEBS Letters 422 274-278

LaPolt PS, Soto D, Su JG, Campen CA, Vaughan J, Vale W and Hsueh AJ (1989) Activin stimulation of inhibin secretion and messenger RNA levels in cultured granulosa cells Molecular Endocrinology 3 1666-1673

Leung PHY, Salamonsen LA and Findlay JK (1998) Immunolocalization of inhibin and activin subunits in human endometrium across the menstrual cycle Human Reproduction 13 3469-3477

*Lewis KA, Gray PC, Blount AL, MacConell LA, Wiater E, Bilezikjian LM and Vale W (2000) Betaglycan binds inhibin and can mediate functional antagonism of activin signalling Nature $\mathbf{4 0 4} 411-414$

Li M, Li JL, Hoodless PA, Tzukazaki T, Wrana JL, Attisano L and Tsang BK (1997) Mothers against decapentaplegic-related protein 2 expression in avian granulosa cells is up-regulated by transforming growth factor beta during ovarian follicular development Endocrinology 138 3659-3665

*Li R, Phillips DM and Mather JP (1995) Activin promotes ovarian follicle development in vitro. Endocrinology 136 849-856

Liu X, Andoh K, Yokota H, Kobayashi J, Abe Y, Yamada K, Mizunuma H and Ibuki Y (1998) Effects of growth hormone, activin, and follistatin on the development of preantral follicle from immature female mice Endocrinology 139 2342-2347

Liu X, Andoh K, Abe Y, Kobayashi J, Yamada K, Mizunuma H and Ibuki Y (1999) A comparative study on transforming growth factor-beta and activin A for preantral follicles from adult, immature, and diethylstilbestrol-primed immature mice Endocrinology 140 2480-2485

Loria P, Petraglia F, Concari M, Bertolotti M, Martella P, Luisi S, Grisolia C, Foresta C, Volpe A, Genazzani AR and Carulli N (1998) Influence of age and sex on serum concentrations of total dimeric activin A European Journal of Endocrinology 139 487-492

Majdic G, McNeilly AS, Sharpe RM, Evans LR, Groome NP and Saunders PT (1997) Testicular expression of inhibin and activin subunits and follistatin in the rat and human fetus and neonate and during postnatal development in the rat Endocrinology 138 2136-2147

Massague J and Chen YG (2000) Controlling TGF-beta signaling Genes and Development 14 627-644

Mathews LS (1994) Activin receptors and cellular signaling by the receptor serine kinase family Endocrine Reviews 15 310-325

*Matzuk MM, Kumar TR and Bradley A (1995) Different phenotypes for mice deficient in either activins or activin receptor type II Nature 374 356-360

Miro F and Hillier SG (1996) Modulation of granulosa cell deoxyribonucleic acid synthesis and differentiation by activin Endocrinology 137 464-468

*Mizunuma H, Liu X, Andoh K, Abe Y, Kobayashi J, Yamada K, Yokota H, Ibuki Y and Hasegawa Y (1999) Activin from secondary follicles causes small preantral follicles to remain dormant at the resting stage Endocrinology $14037-42$

Muttukrishna S, Fowler PA, George L, Groome NP and Knight PG (1996) Changes in peripheral serum levels of total activin A during the human menstrual cycle and pregnancy Journal of Clinical Endocrinology and Metabolism 81 3328-3334

Nakamura M, Minegishi T, Hasegawa Y, Nakamura K, Igarashi S, Ito I, Shinozaki H, Miyamoto K, Eto Y and Ibuki Y (1993) Effect of an activin A on follicle-stimulating hormone $(\mathrm{FSH})$ receptor messenger ribonucleic 
acid levels and FSH receptor expressions in cultured rat granulosa cells Endocrinology 133 538-544

Nomura M and Li E (1998) Smad2 role in mesoderm formation, left-right patterning and craniofacial development Nature 393 786-790

Oh SP and Li E (1997) The signaling pathway mediated by the type IIB activin receptor controls axial patterning and lateral asymmetry in the mouse Genes and Development 11 1812-1826

Osterlund C and Fried G (2000) TGFbeta receptor types I and II and the substrate proteins smad 2 and 3 are present in human oocytes Molecular Human Reproduction 6 498-503

Otani T, Minami S, Kokawa K, Shikone T, Yamoto M and Nakano R (1998) Immunohistochemical localization of activin $\mathrm{A}$ in human endometrial tissues during the menstrual cycle and in early pregnancy Obstetrics and Gynecology 91 685-692

Peng C, Ohno T, Koh LY, Chen VTS and Leung PCK (1999) Human ovary and placenta express messenger RNA for multiple activin receptors Life Sciences 64 983-994

Petraglia F, Florio P, Gallinelli A, De Micheroux AA, Ferrari A, De Vita D, Aguzzoli L, Genazzani AD and Di Carlo C (1994) Secretion and putative role of activin and CRF in human parturition Annals of the New York Academy of Sciences 734 380-386

Phillips DJ and de Kretser DM (1998) Follistatin: a multifunctional regulatory protein Frontiers in Neuroendocrinology 19 287-322

Risbridger GP and Cancilla B (2000) Role of activins in the male reproductive tract Reviews of Reproduction 5 99-104

Roberts V, Meunier H, Vaughan J, Rivier J, Rivier C, Vale W and Sawchenko P (1989) Production and regulation of inhibin subunits in pituitary gonadotropes Endocrinology 124 552-554

Roberts VJ, Barth S, el-Roeiy A and Yen SS (1993) Expression of inhibin/ activin subunits and follistatin messenger ribonucleic acids and proteins in ovarian follicles and the corpus luteum during the human menstrual cycle Journal of Clinical Endocrinology and Metabolism 77 1402-1410
Roberts VJ, Barth S, el-Roeiy A and Yen SS (1994) Expression of inhibin/ activin system messenger ribonucleic acids and proteins in ovarian follicles from women with polycystic ovarian syndrome Journal of Clinical Endocrinology and Metabolism 79 1434-1439

Robertson DM, Hertan R and Farnworth PG (2000) Is the action of inhibin mediated via a unique receptor? Reviews of Reproduction 5 131-135

Shukovski L and Findlay JK (1990) Activin A inhibits oxytocin and progesterone production by preovulatory bovine granulosa cells in vitro. Endocrinology 126 2222-2224

Tanimoto Y, Tanimoto K, Sugiyama F, Horiguchi H, Murakami K, Yagami K and Fukamizu A (1999) Male sterility in transgenic mice expressing activin betaA subunit gene in testis Biochemical and Biophysical Research Communications 259 699-705

Wada M, Shintani Y, Kosaka M, Sano T, Hizawa K and Saito S (1996) Immunohistochemical localization of activin A and follistatin in human tissues Endocrine Journal 43 375-385

Wilson ME and Handa RJ (1998) Activin subunit, follistatin, and activin receptor gene expression in the prepubertal female rat pituitary Biology of Reproduction 59 278-283

Woodruff TK (1998) Regulation of cellular and system function by activin Biochemical Pharmacology 55 953-963

Woodruff TK, Krummen L, McCray G and Mather JP (1993) In situ ligand binding of recombinant human $\left[{ }^{125} \mathrm{I}\right]$ activin $\mathrm{A}$ and recombinant human ${ }^{125}$ I] inhibin-A to the adult rat ovary Endocrinology 133 2998-3006

Wu TC, Jih MH, Wang L and Wan YJ (1994) Expression of activin receptor II and IIB mRNA isoforms in mouse reproductive organs and oocytes Molecular Reproduction and Development 38 9-15

Yamoto M, Minami S, Nakano R and Kobayashi M (1992) Immunohistochemical localization of inhibin/activin subunits in human ovarian follicles during the menstrual cycle Journal of Clinical Endocrinology and Metabolism 74 989-993 